\title{
Wogonin ameliorates lipotoxicity-induced apoptosis of cultured vascular smooth muscle cells via interfering with DAG-PKC pathway
}

\author{
Yu-min LIU $^{1}$, Xiong WANG ${ }^{2}$, Ahmed NAWAZ ${ }^{3}$, Zhao-hong KONG ${ }^{1}$, Yan HONG ${ }^{1}$, Chang-hua WANG ${ }^{3}$, Jun-jian ZHANG ${ }^{1, *}$ \\ ${ }^{1}$ Department of Neurology, Zhongnan Hospital of Wuhan University, Wuhan 430071, China; ${ }^{2}$ Department of Pathophysiology, Hubei \\ University of Medicine, Shiyan 442000, China; ${ }^{3}$ Department of Pathophysiology, Wuhan University School of Medicine, Wuhan \\ 430070, China
}

\begin{abstract}
Aim: To investigate the effects of wogonin (5,7-dihydroxy-8-methoxyflavone) extracted from Scutellaria baicalensis Georgi (S baicalensis) on lipotoxicity-induced apoptosis of vascular smooth muscle cells (VSMCs) and the underlying mechanisms.

Methods: Cultured VSMCs were used. Apoptosis of VSMCs was induced by palmitate $(0.75 \mathrm{mmol} / \mathrm{L})$, and detected using TUNEL assay. The expression levels of protein and phosphorylated protein were measured using Western blot analysis.

Results: Treatment of VSMCs with wogonin (10, 25 and $50 \mu \mathrm{mol} / \mathrm{L})$ significantly attenuated the apoptosis and endoplasmic reticulum (ER) stress induced by palmitate in concentration- and time-dependent manners. Wogonin ( $50 \mu \mathrm{mol} / \mathrm{L})$ decreased palmitate-induced reactive oxygen species (ROS) generation. The ER stress inhibitor 4-phenyl butyric acid ( $5 \mathrm{mmol} / \mathrm{L})$ significantly decreased palmitateinduced apoptotic cells, and occluded the anti-apoptotic effect of wogonin (25 $\mu \mathrm{mol} / \mathrm{L})$. Wogonin (10, 25 and $50 \mu \mathrm{mol} / \mathrm{L})$ significantly reduced the intracellular diacylglycerol (DAG) accumulation and expression levels of phosphorylated PKCs in palmitate-treated VSMCs. Conclusion: Our results suggest that wogonin inhibits lipotoxicity-induced apoptosis of VSMCs via suppressing the intracellular DAG accumulation and subsequent inhibition of PKC phosphorylation. Wogonin has therapeutic potential for the prevention and treatment of atherosclerosis.
\end{abstract}

Keywords: wogonin; atherosclerosis; vascular smooth muscle cells; apoptosis; endoplasmic reticulum stress; palmitate; diacylglycerol (DAG); PKC

Acta Pharmacologica Sinica (2011) 32: 1475-1482; doi: 10.1038/aps.2011.120; published online 10 Oct 2011

\section{Introduction}

Diabetes mellitus is a major contributor to cerebrovascular and cardiovascular disease morbidity and mortality worldwide. Increased free fatty acid (FFA) levels in the plasma caused lipotoxicity, which is a hallmark of diabetes mellitus and leads to an increased risk of atherosclerosis and cardiovascular diseases $^{[1-3]}$. Strong evidence has suggested that elevated FFA levels in the plasma enhance the intracellular accumulation of diacylglycerol (DAG), which leads to the activation of protein kinase Cs (PKCs), inhibitor kappaB kinase (IKK), or c-Jun $\mathrm{N}$-terminal kinase (JNK), resulting in atherosclerotic plaque development and instability ${ }^{[4,5]}$. Therefore, the plasma FFA and intracellular DAG levels represent selective targets to prevent atherosclerosis.

Vascular smooth muscle cells (VSMCs) play a pivotal role

\footnotetext{
* To whom correspondence should be addressed.

E-mail wdsjkx@163.com

Received 2011-01-08 Accepted 2011-07-25
}

in the initiation and early progression of atherosclerosis and plaque rupture ${ }^{[6,7]}$. Due to the important function of synthesizing components of the fibrous cap in plaques, VSMCs are responsible for promoting plaque stability in advanced atherosclerotic lesions. Published evidence has shown that VSMC apoptosis precipitates a number of deleterious consequences in atherosclerosis, such as plaque rupture ${ }^{[7-12]}$. Therefore, antiapoptotic therapies for VSMCs may benefit the prevention and treatment of atherosclerosis ${ }^{[8,10]}$.

Scutellaria baicalensis Georgi (S baicalensis) is a traditional Chinese herb (Baikal Skullcap) that is widely used for the treatment of inflammation, infection, cancer, hypertension, and cardiovascular disease ${ }^{[13,14]}$. Wogonin (5,7-dihydroxy-8-methoxyflavone) is a major bioactive component of the flavonoids from $S$ baicalensis. Pharmacological findings have highlighted the therapeutic potential regarding the use of plant-derived wogonin to modulate endothelial cell and VSMC function for the prevention and treatment of atherosclerosis ${ }^{[15-17]}$. However, the underlying mechanism is poorly understood. 
In this study, our results show that wogonin attenuates lipotoxicity-induced apoptosis and inhibits endoplasmic reticulum (ER) stress by suppressing intracellular DAG accumulation, which perturbs the DAG/PKC pathway in cultured VSMCs. This novel finding supplies evidence for the potential administration of wogonin for the treatment of atherosclerosis.

\section{Materials and methods Materials and reagents}

Biochemical reagents were obtained from the following sources: palmitic acid, tunicamycin, wogonin $\left(\mathrm{C}_{16} \mathrm{H}_{12} \mathrm{O}_{5}\right)$ (Figure 1), 4-phenyl butyric acid (4-PBA) from Sigma (St Louis, MO, USA); the anti-CHOP antibody, anti-cleaved caspase-3 antibody, anti-cleaved caspase- 6 antibody, anti-eIF2 $\alpha$ antibody, anti-phosphorylated-eIF2a Ser51 antibody, anti-Bcl-2 antibody, anti-Bax antibody, PKC isoform antibody sampler kit, and phosphorylated-PKC isoform antibody sampler kit from Cell Signaling Technology; and secondary antibodies that were conjugated to alkaline phosphatase from Promega. The APO-BrdUTM TUNEL Assay Kit was purchased from Invitrogen. The ELISA Kit for DAG was obtained from Uscn Life Science, Inc (Wuhan, China).

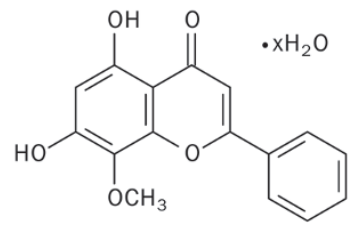

Figure 1. Chemical structure of wogonin.

\section{Cell culture and treatment}

Vascular smooth muscle cells (SV40LT-SMC Clone HEP-SA, ATCC CRL-2018 ${ }^{\mathrm{TM}}$ ) were cultured in growth medium (Dulbecco's modified Eagle's medium with $4 \mathrm{mmol} / \mathrm{L}$ L-glutamine, which was adjusted to contain $1.5 \mathrm{~g} / \mathrm{L}$ sodium bicarbonate and $4.5 \mathrm{~g} / \mathrm{L}$ glucose, $0.2 \mathrm{mg} / \mathrm{mL} \mathrm{G418}$, and $10 \%$ bovine calf serum). A10 VSMCs (ATCC CRL-1476 ${ }^{\mathrm{TM}}$ ) were incubated in DMEM (ATCC 30-2002) containing 10\% FBS and $1.0 \mathrm{~g} / \mathrm{L}$ sodium bicarbonate. The culture conditions were $37.0^{\circ} \mathrm{C}, 95 \%$ $\mathrm{O}_{2}$, and $5 \% \mathrm{CO}_{2}$. For treatment, the cells were serum-starved for $6 \mathrm{~h}$ and then incubated with palmitate and/or wogonin for the desired exposure time. The preparation of palmitate was as described in our previous study ${ }^{[18]}$. Briefly, palmitic acid was dissolved in ethanol, mixed with $20 \%$ BSA and then incubated overnight at $4^{\circ} \mathrm{C}$. The solution was filtered, stored at $-20^{\circ} \mathrm{C}$ and used within 2 weeks. The same concentration of ethanol was mixed with $20 \%$ BSA and used as a control.

\section{Western blot analysis}

The cells were lysed with lysis buffer $(50 \mathrm{mmol} / \mathrm{L}$ Hepes, $\mathrm{pH}$ 7.6, $150 \mathrm{mmol} / \mathrm{L} \mathrm{NaCl}, 1 \%$ Triton X-100, $10 \mathrm{mmol} / \mathrm{L} \mathrm{NaF}, 20$ $\mathrm{mmol} / \mathrm{L}$ sodium pyrophosphate, $20 \mathrm{mmol} / \mathrm{L} \beta$-glycerol phosphate, $1 \mathrm{mmol} / \mathrm{L}$ sodium orthovanadate, $10 \mu \mathrm{g} / \mathrm{mL}$ leupeptin,
$10 \mu \mathrm{g} / \mathrm{mL}$ aprotinin, and $1 \mathrm{mmol} / \mathrm{L}$ phenylmethanesulfonyl fluoride). The cell lysates were incubated on ice for 10 min and then centrifuged at $14000 \times g$ for $10 \mathrm{~min}$ at $4{ }^{\circ} \mathrm{C}$. The supernatants were mixed with equal volumes of $2 \times$ SDS-PAGE sample loading buffer. After heating at $95^{\circ} \mathrm{C}$ for $4 \mathrm{~min}$, the proteins were separated using a SDS-PAGE gel, transferred to a nitrocellulose membrane, and detected with the aforementioned antibodies.

\section{Apoptosis determination}

Terminal deoxynucleotidyl transferase-mediated dUTPbiotin nick end-labeling (TUNEL) was performed to detect cells undergoing apoptosis according to the manufacturer's protocol. Briefly, VSMCs were treated with palmitate and/ or wogonin, washed with cold PBS three times and then fixed with $1 \%$ of paraformaldehyde on ice for $1 \mathrm{~h}$. After washing three times with PBS, the cells were treated with $70 \%$ ethanol and incubated at $-20^{\circ} \mathrm{C}$ for $24 \mathrm{~h}$. The cells were washed with wash buffer 3 times and incubated in DNA-labeling solution (including terminal deoxynucleotidyl transferase enzyme and BrdU triphosphate) at $37^{\circ} \mathrm{C}$ for $1 \mathrm{~h}$. The cells were rinsed with PBS, collected by centrifugation, and incubated in anti-BrdUstaining mix for $45 \mathrm{~min}$ at room temperature. The apoptotic nuclei containing nicked DNA were stained brown. To calculate the apoptosis rate, 1000 nuclei were identified in 20 random high power fields per slide.

\section{Extraction and measurement of DAG}

Total DAG levels were measured using an ELISA Assay Kit (Uscn Life Science Inc, Wuhan, China) according to the manufacturer's protocol. Briefly, the serum-starved VSMCs $\left(1 \times 10^{6}\right.$ cells / well in 6 -well dishes $)$ were incubated with or without different doses of palmitate and/or wogonin for the desired time. Total cell lipids were extracted with chloroform:methanol $(1: 2, v / v)$ after centrifugation at $5000 \times g$ for $2 \mathrm{~min}^{[19]}$. The lower chloroform phase was analyzed for DAG contents.

\section{Measurement of reactive oxygen species}

Intracellular reactive oxygen species (ROS) production was measured using the method of Shaw et al ${ }^{[20]}$. Briefly, VSMCs were plated in a 24 -well plate at a density of $2 \times 10^{4}$ cells/well in DMEM, serum-starved for $6 \mathrm{~h}$, and treated with or without different doses of palmitate and/or wogonin for the desired time. The cells were washed with modified Eagle's medium without phenol red and incubated in the dark for $10 \mathrm{~min}$ in Krebs-Ringer solution containing $50 \mu \mathrm{mol} / \mathrm{L}$ DCHF diacetate. Changes in fluorescence intensity were determined using an Flx-800 microplate fluorescence reader (Bio-Tek Instruments) at excitation and emission wavelengths at 485 and $528 \mathrm{~nm}$, respectively ${ }^{[19,20]}$.

\section{Statistical analysis}

Three independent experiments were performed with each sample in triplicate. The data were expressed as the mean \pm SEM. Statistical analysis was performed using analysis 
of variance followed by Student's $t$-test for paired data. $P<0.05$ was considered significant. The figures are representative of at least three independent experiments with similar results.

\section{Results}

\section{Effects of wogonin on palmitate-induced apoptosis}

Wogonin modulates endothelial cell and VSMC functions to promote its anti-atherosclerotic effects ${ }^{[15-17]}$. Considering the pivotal roles of VSMC apoptosis ${ }^{[7-12]}$ and the elevated plasma FFA levels ${ }^{[4,5]}$ in atherosclerotic plaque ruptures, we investigated the potential effects of wogonin on palmitate-induced VSMC apoptosis. The serum-starved VSMCs were treated with different doses of wogonin for the desired time in the presence of $0.75 \mathrm{mmol} / \mathrm{L}$ palmitate for $24 \mathrm{~h}$. As shown in Figure $2 \mathrm{~A}$ and $2 \mathrm{~B}$, wogonin significantly attenuated the palmitateinduced apoptosis in a dose- and time-dependent manner. We evaluated the expression levels of cleaved caspase-3 and caspase- 6 because activation of the caspase- 3 pathway is a hallmark of apoptosis ${ }^{[21-23]}$. We found that wogonin inhibited the expression of cleaved caspase- 3 and caspase- 6 in a dose- and time-dependent manner in VSMCs that were pre-treated with $0.75 \mathrm{mmol} / \mathrm{L}$ palmitate (Figure $2 \mathrm{C}$ and 2D). The anti-apoptotic Bcl-2 and pro-apoptotic Bax proteins are among many key regulators of apoptosis. Therefore, we investigated the effects of wogonin on these regulatory proteins. We treated A10 VSMCs with $0.75 \mathrm{mmol} / \mathrm{L}$ palmitate for $12 \mathrm{~h}$ followed by treatment with $25 \mu \mathrm{mol} / \mathrm{L}$ wogonin for an additional $12 \mathrm{~h}$. We found that wogonin restored $\mathrm{Bcl}-2$ expression and decreased Bax expression, which consequently restored the ratio of $\mathrm{Bcl}-2$ to Bax (Figure 3). These data suggest that wogonin protects VSMCs from palmitate-induced apoptosis.

\section{Effects of wogonin on palmitate-induced ER stress}

To identify the signaling pathway that initialized apoptosis, VSMCs were serum-starved by culturing in serum-free medium. Serum-starved VSMCs were treated with wogonin in a dose- and time-dependent manner in culture medium with $0.75 \mathrm{mmol} / \mathrm{L}$ palmitate. The levels of CHOP expression and eIF2a phosphorylation for these cells were analyzed using the Western blot analysis as stated under the Materials and methods. As shown in Figure 4A and 4B, palmitateinduced $\mathrm{CHOP}$ expression and eIF2a phosphorylation were suppressed by wogonin in a dose- and time-dependent manner similar to that observed in wogonin-mediated suppression of cleaved caspase- 3 and caspase- 6 expression and apoptosis. Apoptosis is initialized by extrinsic (activated by death ligands), intrinsic (mitochondrial pathway), or ER stress pathways ${ }^{[21-23]}$. We treated VSMCs to discover the potential anti-apoptotic effects of wogonin so that we could determine whether ER stress mediated the inhibitory effects of wogonin on apoptosis. 4-PBA ( $5 \mathrm{mmol} / \mathrm{L}$ ) was used to inhibit ER stress in A10 VSMCs that were treated with $0.75 \mathrm{mmol} / \mathrm{L}$ palmitate and/or $25 \mathrm{mmol} / \mathrm{L}$ wogonin. We found that administration of 4-PBA significantly decreased the number of apoptotic cells in A10 VSMCs that were treated with palmitate and that wogonin treatment did not further enhance the inhibitory
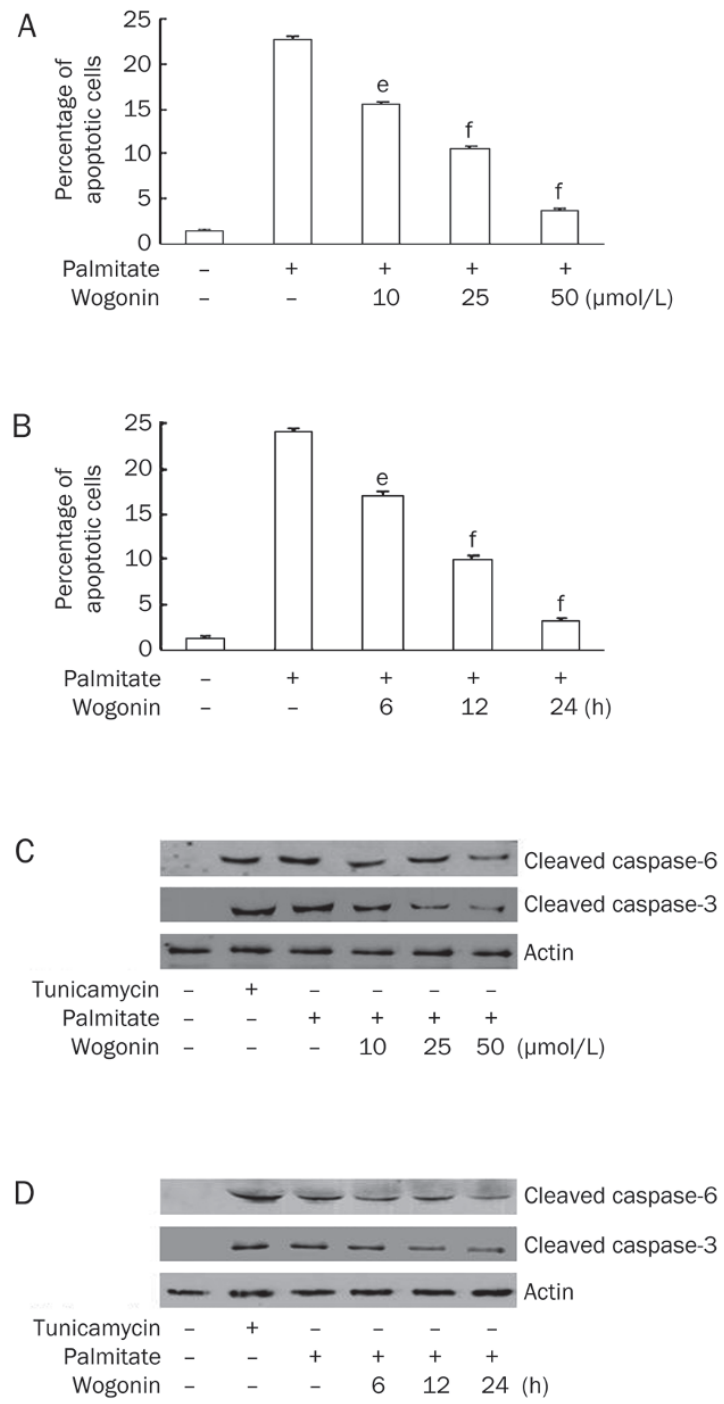

Figure 2. Wogonin prevented palmitate-induced apoptosis. VSMCs were cultured in serum-free medium for $6 \mathrm{~h}$ and treated with or without 0.75 $\mathrm{mmol} / \mathrm{L}$ of palmitate for $12 \mathrm{~h}$, followed by a second treatment with or without 10, 25, and $50 \mu \mathrm{mol} / \mathrm{L}$ of wogonin for an additional $12 \mathrm{~h}$ (A and C) or $25 \mu \mathrm{mol} / \mathrm{L}$ of wogonin for 6,12 , and $24 \mathrm{~h} \mathrm{(B}$ and $D$ ). ( $A$ and $B$ ) The effects of wogonin on the percentage of apoptotic cells. Apoptotic cells were visualized using TUNEL methods. ${ }^{e} P<0.05$; ${ }^{f} P<0.01$ compared with the palmitate-treated group. ( $C$ and $D$ ) The effects of wogonin on cleaved caspase- 3 and caspase- 6 expression. In total, $5 \mu \mathrm{g} / \mathrm{mL}$ of tunicamycin (18 h) was used as a positive control. The expression levels of cleaved caspase- 3 and caspase- 6 were detected using Western blotting. The figures are representative of at least three independent experiments with similar results.

effects (Figure 5). These data suggest that palmitate-induced apoptosis and wogonin-mediated protection against apoptosis are mediated by ER stress. Taken together, these data indicate that wogonin promotes anti-apoptotic effects via inhibition of ER stress.

Effects of wogonin on palmitate-induced ROS generation

Over-generation of ROS is responsible for apoptosis in FFA- 
A
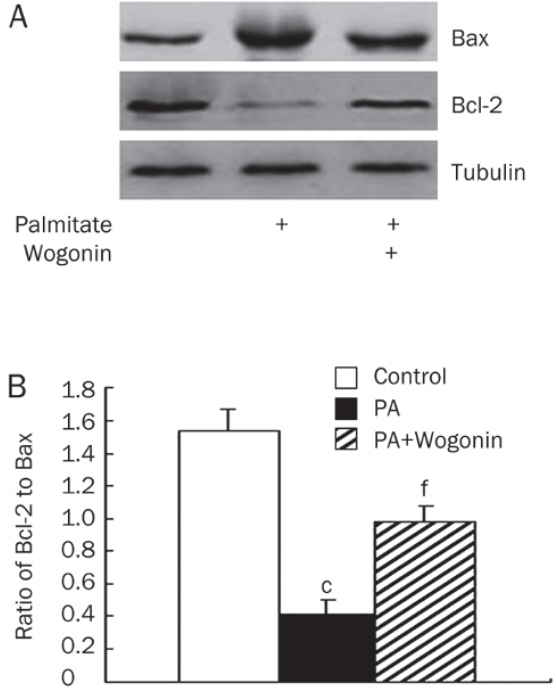

Figure 3. Wogonin restored the ratio of $\mathrm{Bcl}-2$ to Bax. A10 VSMCs were cultured in serum-free medium for $6 \mathrm{~h}$ and treated with $0.75 \mathrm{mmol} / \mathrm{L}$ of palmitate (PA) for $12 \mathrm{~h}$, followed by a second treatment with or without $25 \mu \mathrm{mol} / \mathrm{L}$ of wogonin for an additional $12 \mathrm{~h}$. (A) Bcl-2 and Bax protein expression. (B) Bar graph for the ratio of $\mathrm{Bcl}-2$ to Bax. Western blot was performed to detect the expression levels of $\mathrm{Bcl}-2$ and Bax. The figures are representative of at least three independent experiments with similar results. ${ }^{\mathrm{c}} P<0.01$ compared with the control group. ${ }^{\mathrm{f}} P<0.01$ compared with the palmitate-treated group.
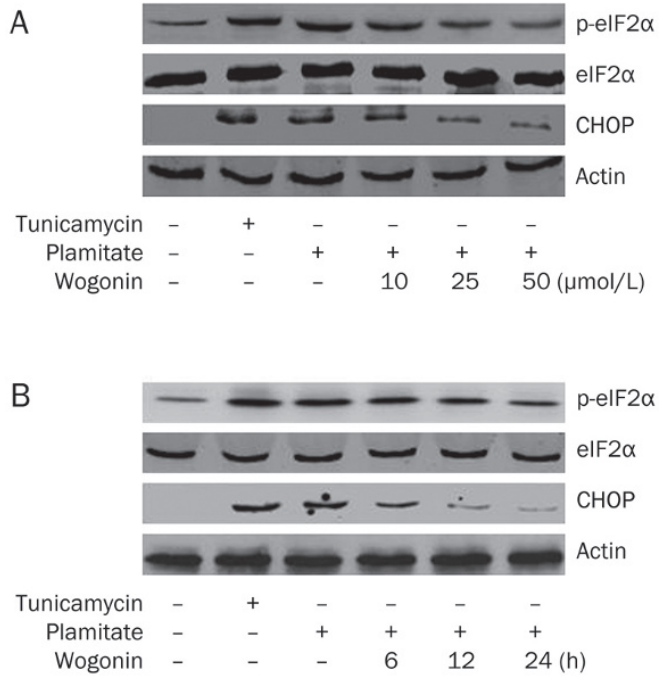

Figure 4. Wogonin inhibited palmitate-induced ER stress. VSMCs were cultured in serum-free medium for $6 \mathrm{~h}$ and treated with or without differential doses of wogonin for the indicated time in the presence of 0.75 $\mathrm{mmol} / \mathrm{L}$ of palmitate or $10 \mathrm{\mu g} / \mathrm{mL}$ of the ER inducer tunicamycin for $24 \mathrm{~h}$. (A) Dose course. In total, 10,25 , or $50 \mu \mathrm{mol} / \mathrm{L}$ of wogonin was added to the culture medium for $24 \mathrm{~h}$. (B) Time course. In total, $50 \mu \mathrm{mol} / \mathrm{L}$ of wogonin was added to the culture medium for 6,12 , or $24 \mathrm{~h}$. Western blot was performed to detect the expression levels of $\mathrm{CHOP}$, elF $2 \alpha$, and phosphorylated elF $2 \alpha$. The figures are representative of at least three independent experiments with similar results.
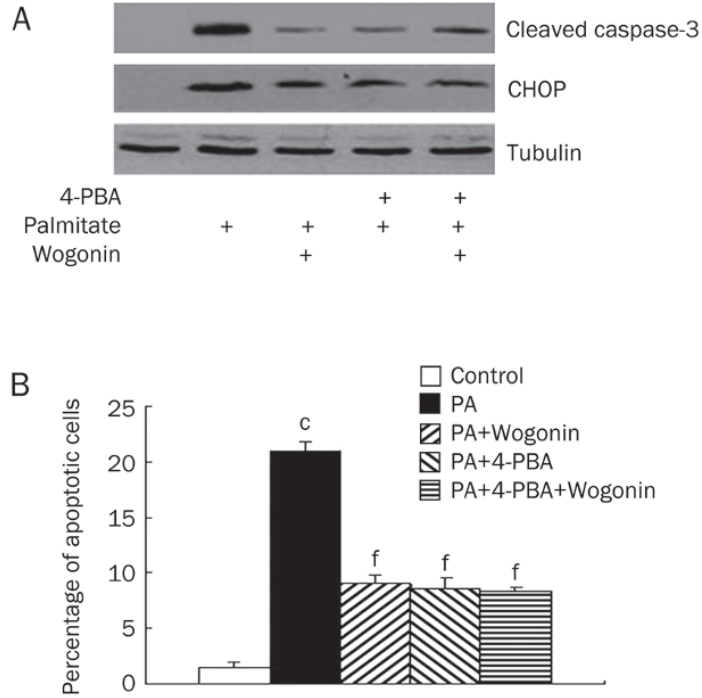

Figure 5. The effects of combined treatment of 4-PBA and wogonin on apoptosis. A10 VSMCs were cultured in serum-free medium for $6 \mathrm{~h}$ and treated with or without 4-PBA ( $5 \mathrm{mmol} / \mathrm{L}$ ) for $1 \mathrm{~h}$, followed by treatment with or without $25 \mu \mathrm{mol} / \mathrm{L}$ of wogonin for $12 \mathrm{~h}$ in the presence of 0.75 $\mathrm{mmol} / \mathrm{L}$ of palmitate (PA) for $24 \mathrm{~h}$. (A) CHOP and cleaved caspase-3 protein expression. (B) Bar graph for percentage of apoptotic cells. Western blot was performed to detect the expression levels of $\mathrm{CHOP}$ and cleaved caspase-3. The figures are representative of at least three independent experiments with similar results. ${ }^{\circ} P<0.01$ compared with the control group; ${ }^{f} P<0.01$ compared with the palmitate-treated group.

treated cells ${ }^{[24-27]}$. We addressed whether wogonin has any effects on palmitate-mediated ROS generation. Serum-starved VSMCs were treated with wogonin in a dose- and time-dependent manner in culture medium with $0.75 \mathrm{mmol} / \mathrm{L}$ palmitate and evaluated to measure ROS generation. As shown in Figure $6 \mathrm{~A}$ and $6 \mathrm{~B}, \mathrm{ROS}$ generation was increased in cells that were treated with palmitate and suppressed after a high dose $(50 \mu \mathrm{mol} / \mathrm{L})$ of wogonin treatment $(P<0.05)$ and long exposure time $(24 \mathrm{~h})(P<0.05)$. These results indicate that the inhibition of ROS generation by wogonin is not a major mechanism for its anti-apoptotic effects.

\section{Effects of wogonin on the DAG/PKC pathway}

Accumulating evidence suggests that the DAG/PKC pathway contributes to deleterious consequences in cells, including apoptosis in response to FFA administration ${ }^{[28-35]}$. Based on this evidence, we hypothesized that wogonin-mediated suppression of apoptosis might counter this mechanism and improve cell survival. To confirm this hypothesis, serumstarved VSMCs were treated with wogonin in a dose- and time-dependent manner in culture medium with $0.75 \mathrm{mmol} / \mathrm{L}$ of palmitate and evaluated to measure intracellular levels of DAG. As expected, palmitate significantly increased the intracellular contents of DAG, which were suppressed by wogonin administration (Figure 7A and 7B). In addition, the administration of wogonin at a dose of $25 \mu \mathrm{mol} / \mathrm{L}$ for $24 \mathrm{~h}$ inhibited palmitate-induced PKC phosphorylation for mul- 

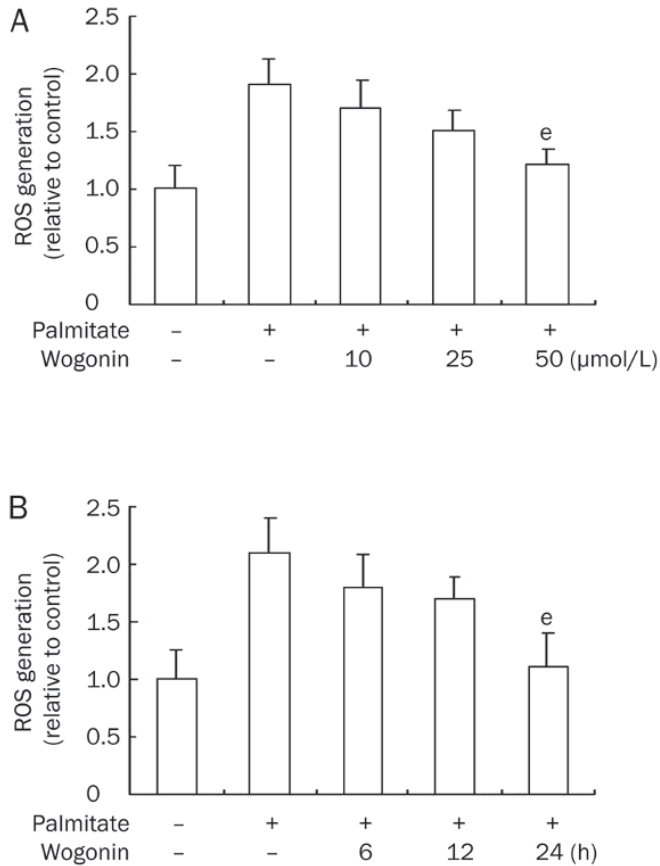

Figure 6. Wogonin suppressed palmitate-induced ROS generation. VSMCs were cultured in serum-free medium for $6 \mathrm{~h}$ and treated with or without different doses of wogonin for the indicated time in the presence of $0.75 \mathrm{mmol} / \mathrm{L}$ of palmitate for $24 \mathrm{~h}$. (A) Dose course. In total, 10, 25, or $50 \mu \mathrm{mol} / \mathrm{L}$ of wogonin was added to the culture medium for $24 \mathrm{~h}$. (B) Time course. In total, $50 \mu \mathrm{mol} / \mathrm{L}$ of wogonin was added to the culture medium for 6,12 , or $24 \mathrm{~h}$. The production of ROS was determined as described in the Materials and methods section. ${ }^{e} P<0.05,{ }^{f} P<0.01$ compared with the palmitate-treated group.

tiple PKC-isozymes (Figure 7C). These observations suggest that wogonin inhibits the DAG/PKC pathway, and attenuates apoptosis when combined with palmitate treatment.

\section{Discussion}

In this study, we demonstrate a protective effect of wogonin on palmitate-induced VSMC apoptosis. Palmitate-induced apoptosis of VSMCs was attenuated by wogonin administration in a dose- and time-dependent manner. The administration of wogonin inhibits the DAG/PKC pathway by downregulating intracellular DAG accumulation and attenuating ER stress.

It is well documented that obese and diabetic patients have increased FFA levels, which induce atherosclerotic vascular disease. Previous studies have shown that even minute increases in plasma FFA may initiate early vascular abnormalities that promote atherosclerosis and cardiovascular disease $(C V D)^{[1]}$. The most abundant saturated fatty acid in the plasma is palmitate. Studies have indicated that palmitate is involved in atherogenesis by increasing the extent of plaque formation (or plaque score) ${ }^{[36]}$ and inducing extracellular matrix alterations ${ }^{[37]}$. In this study, we found that the administration of palmitate induced VSMC apoptosis (Figure 2). VSMCs synthesize components of the fibrous cap in plaques.
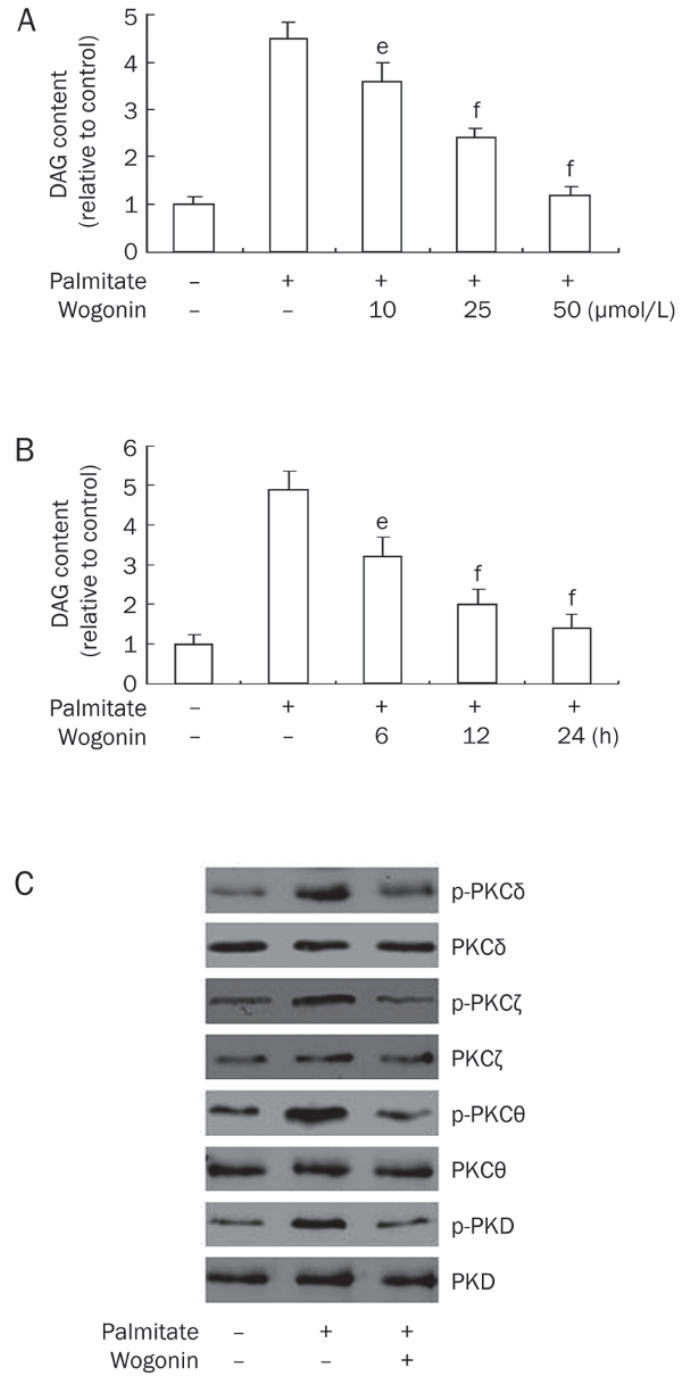

Figure 7. Wogonin ameliorated intracellular DAG accumulation and attenuated PKC phosphorylation. (A and B) VSMCs were cultured in serum-free medium for $6 \mathrm{~h}$ and treated with or without $0.75 \mathrm{mmol} / \mathrm{L}$ of palmitate for $12 \mathrm{~h}$, followed by a second treatment with or without 10 , 25 , and $50 \mu \mathrm{mol} / \mathrm{L}$ of wogonin for an additional $12 \mathrm{~h} \mathrm{(A)}$ or $25 \mu \mathrm{mol} / \mathrm{L}$ of wogonin for 6,12 , and $24 \mathrm{~h}(\mathrm{~B})$. DAG content in the cells was determined as described in the Materials and methods section. ${ }^{\mathrm{e}} P<0.05,{ }^{\mathrm{f}} P<0.01$ compared with the palmitate-treated group. (C) VSMCs were cultured in serum-free medium for $6 \mathrm{~h}$ and treated with or without $25 \mu \mathrm{mol} / \mathrm{L}$ of wogonin for $12 \mathrm{~h}$ in the presence of $0.75 \mathrm{mmol} / \mathrm{L}$ of palmitate for $24 \mathrm{~h}$. Western blot analysis was performed to detect the expression levels of total and phosphorylated PKC isoforms. The figures are representative of at least three independent experiments with similar results.

Therefore, VSMC apoptosis may result in plaque ruptures ${ }^{[7-12]}$. Our results indicate a potential mechanism for FFA-induced plaque rupture.

Apoptosis can be initialized through an extrinsic pathway that is activated via death ligands, the intrinsic pathway (mitochondrial pathway), or the ER stress pathway that converges on the activation of caspase- $3^{[21-23]}$. Our results confirm that palmitate significantly increases $\mathrm{CHOP}$ protein expression and 
eIF2a phosphorylation (Figure 4).

We detected the increased expression of cleaved caspase-3 and caspase- 6 (Figure 2), and the decreased ratio of antiapoptotic protein $\mathrm{Bcl}-2$ to pro-apoptotic protein Bax (Figure 3). Furthermore, the ER stress inhibitor 4-PBA prevented palmitate-induced apoptosis (Figure 5), which indicated that palmitate-induced apoptosis of VSMCs was mediated by ER stress. These data are congruent with previous studies showing that palmitate is a potent inducer of ER stress ${ }^{[38]}$. Recent evidence shows that atherosclerosis is associated with ER dysfunction and the accumulation of unfolded proteins ${ }^{[39-43]}$. Suppressing ER-stress signaling significantly attenuates accelerated atherogenesis ${ }^{[40]}$. The results of the current study suggest that increased FFA levels enhance ER stress, which may be an important risk factor in the induction of VSMC apoptosis in atherosclerosis.

Wogonin has recently been shown to be toxic in malignant cells but has no or little toxicity in normal cells ${ }^{[44-46]}$. Wogonin selectively induces apoptosis in tumor cells but has protective effects on glucocorticoid-induced apoptosis in normal rat thymocytes ${ }^{[46]}$. This selective antitumor function is largely due to its abilities to reduce inflammation, scavenge oxidative radicals, attenuate NF-KB activity, inhibit several genes that are important for regulation of the cell cycle, suppress COX-2 gene expression, block $\mathrm{NO}$, and prevent viral infections ${ }^{[13,47-49]}$. Our results demonstrate that wogonin attenuates palmitateinduced apoptosis of VSMCs in a dose- and time-dependent manner (Figure 2), which is accompanied by the suppression of ER stress (Figure 4). When ER stress was inhibited by 4-PBA, the administration of wogonin did not enhance its protective effects on apoptosis (Figure 5). Therefore, these data confirm that the inhibitory effects of wogonin on apoptosis are mediated by the suppression of ER stress.

ER and oxidative stresses are common manifestations in cells that are treated with FFA. The effect of FFA on ROS production has been examined in numerous cell types ${ }^{[50,51]}$. ER stress and ROS are proposed to be involved in cell death. Nevertheless, their relative involvements in the processes leading to cell apoptosis are not well elucidated. Research groups have confirmed that over-generation of intracellular ROS might induce apoptosis in endothelial cells, beta cells, and retinal pericytes ${ }^{[24-27]}$. In contrast, some data shows that apoptosis may not be caused by increased ROS in VSMCs and neonatal cardiomyocytes that are incubated with palmitate ${ }^{[52,53]}$. Our results show that palmitate increases ROS generation (Figure 6). Although the administration of wogonin at doses of 10 $\mu \mathrm{mol} / \mathrm{L}$ and $25 \mu \mathrm{mol} / \mathrm{L}$ significantly reduced apoptosis (Figure 2), no effects where observed on ROS generation (Figure 6). These results suggest that palmitate-induced ROS generation may not be the major cause of apoptosis in VSMCs.

Furthermore, we found that palmitate increased the intracellular accumulation of DAG and consequently enhanced PKC phosphorylation (Figure 7). This result coincides with previous studies showing that saturated non-esterified fatty acids stimulate an increase in de novo intramuscular synthesis and accumulation of $\mathrm{DAG}^{[31,32]}$ and the subsequent activation of PKCs ${ }^{[28-30,33-35]}$. Our results show that pre-treatment with wogonin significantly reduces the intracellular DAG levels and attenuates PKC phosphorylation (Figure 7). Because activated PKCs may contribute to altered cellular functions such as regulating signaling function of the $\mathrm{ER}^{[54,55]}$ and enhancing ROS production ${ }^{[51]}$, our data suggest that the DAG/PKC pathway mediates palmitate-induced apoptosis and overgenerated ROS production in VSMCs, and that wogonin ameliorates palmitate-induced ER stress by inhibiting the DAGPKC pathway.

In conclusion, we provide novel evidence that wogonin attenuates lipotoxicity-induced apoptosis by suppressing intracellular DAG accumulation and inhibiting PKC phosphorylation in cultured VSMCs. However, further studies are necessary to determine whether the administration of wogonin will protect in vivo VSMCs from apoptosis and the subsequent rupture of advanced atherosclerotic plaques. Additional research into wogonin is also required to investigate the underlying mechanisms that suppress intracellular DAG accumulation in VSMCs.

\section{Acknowledgements}

We would like to thank Levi FROKE and Michael FREITAG (University of South Dakota, USA) for editing the manuscript for English grammar.

\section{Author contribution}

Yu-min LIU, Chang-hua WANG, and Jun-jian ZHANG designed the research; Xiong WANG, Ahmed NAWAZ, and Zhao-hong KONG performed the research; Yan HONG contributed new reagents and analytic tools; Yu-min LIU and Yan HONG analyzed the data; and Chang-hua WANG and Junjian ZHANG wrote the paper.

\section{Abbreviations}

DAG, diacylglycerol; DMEM, Dulbecco's modified Eagle's medium; ER, endoplasmic reticulum; FBS, fetal bovine serum; FFA, free fatty acid; PKC, protein kinase C; ROS, reactive oxygen species; VSMC, vascular smooth muscle cell; PBS, phosphate-buffered saline.

\section{References}

1 Mathew M, Tay E, Cusi K. Elevated plasma free fatty acids increase cardiovascular risk by inducing plasma biomarkers of endothelial activation, myeloperoxidase and PAI-1 in healthy subjects. Cardiovasc Diabetol 2010; 9: 9.

2 Gade W, Schmit J, Collins M, Gade J. Beyond obesity: the diagnosis and pathophysiology of metabolic syndrome. Clin Lab Sci 2010; 23: 51-61.

3 Boden G. Obesity and free fatty acids. Endocrinol Metab Clin North Am 2008; 37: 635-46.

4 Pilz S, März W. Free fatty acids as a cardiovascular risk factor. Clin Chem Lab Med 2008; 46: 429-34.

5 Montecucco F, Steffens S, Mach F. Insulin resistance: a proinflammatory state mediated by lipid-induced signaling dysfunction and involved in atherosclerotic plaque instability. Mediators Inflamm 2008; 2008: 767623. 
6 Doran AC, Meller N, McNamara CA. Role of smooth muscle cells in the initiation and early progression of atherosclerosis. Arterioscler Thromb Vasc Biol 2008; 28: 812-9.

7 Rudijanto A. The role of vascular smooth muscle cells on the pathogenesis of atherosclerosis. Acta Med Indones 2007; 39: 86-93.

8 Clarke M, Bennett M. The emerging role of vascular smooth muscle cell apoptosis in atherosclerosis and plaque stability. Am J Nephrol 2006; 26: 531-5.

9 Clarke M, Bennett M. Defining the role of vascular smooth muscle cell apoptosis in atherosclerosis. Cell Cycle 2006; 5: 2329-31.

10 Stoneman VE, Bennett MR. Role of apoptosis in atherosclerosis and its therapeutic implications. Clin Sci (Lond) 2004; 107: 343-54.

11 Newby AC, Libby P, van der Wal AC. Plaque instability: the real challenge for atherosclerosis research in the next decade? Cardiovasc Res 1999; 41: 321-2.

12 Bennett MR. Apoptosis of vascular smooth muscle cells in vascular remodelling and atherosclerotic plaque rupture. Cardiovasc Res 1999; 41: 361-8.

13 Li-Weber M. New therapeutic aspects of flavones: the anticancer properties of Scutellaria and its main active constituents Wogonin, Baicalein and Baicalin. Cancer Treat Rev 2009; 35: 57-68.

14 Huang Y, Tsang SY, Yao X, Chen ZY. Biological properties of baicalein in cardiovascular system. Curr Drug Targets Cardiovasc Haematol Disord 2005; 5: 177-84.

15 Lee SO, Jeong YJ, Yu MH, Lee JW, Hwangbo $\mathrm{MH}$, Kim CH, et al. Wogonin suppresses TNF-alpha-induced MMP-9 expression by blocking the NF-kappaB activation via MAPK signaling pathways in human aortic smooth muscle cells. Biochem Biophys Res Commun 2006; 351: 118-25.

16 Chang YL, Shen JJ, Wung BS, Cheng JJ, Wang DL. Chinese herbal remedy wogonin inhibits monocyte chemotactic protein-1 gene expression in human endothelial cells. Mol Pharmacol 2001; 60: 507-13.

17 Huang HC, Wang HR, Hsieh LM. Antiproliferative effect of baicalein, a flavonoid from a Chinese herb, on vascular smooth muscle cell. Eur J Pharmacol 1994; 251: 91-3.

18 Wang C, Liu M, Riojas RA, Xin X, Gao Z, Wu J, et al. Protein Kinase C \{theta\} (PKC\{theta\})-dependent phosphorylation of PDK1 at Ser504 and Ser532 contributes to palmitate-induced insulin resistance. J Biol Chem 2009; 284: 2038-44.

19 Ramana KV, Friedrich B, Tammali R, West MB, Bhatnagar A, Srivastava SK. Requirement of aldose reductase for the hyperglycemic activation of protein kinase $\mathrm{C}$ and formation of diacylglycerol in vascular smooth muscle cells. Diabetes 2005; 54: 818-29.

20 Shaw S, Wang X, Redd H, Alexander GD, Isales CM, Marrero MB. High glucose augments the angiotensin II-induced activation of JAK2 in vascular smooth muscle cells via the polyol pathway. J Biol Chem 2003; 278: 30634-41.

21 Hitomi J, Katayama T, Eguchi Y, Kudo T, Taniguchi M, Koyama Y, et al. Involvement of caspase-4 in endoplasmic reticulum stress-induced apoptosis and Abeta-induced cell death. J Cell Biol 2004; 165: $347-$ 56.

22 Morishima N, Nakanishi K, Takenouchi H, Shibata T, Yasuhiko Y. An endoplasmic reticulum stress-specific caspase cascade in apoptosis. Cytochrome $c$-independent activation of caspase-9 by caspase-12. J Biol Chem 2002; 277: 34287-94.

23 Nakagawa T, Zhu H, Morishima N, Li E, Xu J, Yankner BA, et al. Caspase-12 mediates endoplasmic-reticulum-specific apoptosis and cytotoxicity by amyloid-beta. Nature 2000; 403: 98-103.

$24 \mathrm{Kim}$ JE, Kim YW, Lee IK, Kim JY, Kang YJ, Park SY. AMP-activated protein kinase activation by 5 -aminoimidazole-4-carboxamide-1-beta-
D-ribofuranoside (AICAR) inhibits palmitate-induced endothelial cell apoptosis through reactive oxygen species suppression. J Pharmacol Sci 2008; 106: 394-403.

25 Cai Y, Martens GA, Hinke SA, Heimberg H, Pipeleers D, Van de Casteele $M$. Increased oxygen radical formation and mitochondrial dysfunction mediate beta cell apoptosis under conditions of AMPactivated protein kinase stimulation. Free Radic Biol Med 2007; 42: 64-78.

26 Iverson SL, Orrenius S. The cardiolipin-cytochrome c interaction and the mitochondrial regulation of apoptosis. Arch Biochem Biophys 2004; 423: 37-46.

27 Yamagishi S, Okamoto T, Amano S, Inagaki Y, Koga M, Choei H, et al. Palmitate-induced apoptosis of microvascular endothelial cells and pericytes. Mol Med 2002; 8: 179-84.

28 Erion DM, Shulman GI. Diacylglycerol-mediated insulin resistance. Nat Med 2010; 16: 400-2.

29 Das Evcimen N, King GL. The role of protein kinase $\mathrm{C}$ activation and the vascular complications of diabetes. Pharmacol Res 2007; 55: 498-510.

30 Wang QJ. PKD at the crossroads of DAG and PKC signaling. Trends Pharmacol Sci 2006; 27: 317-23.

31 Lee JS, Pinnamaneni SK, Eo SJ, Cho IH, Pyo JH, Kim CK, et al. Saturated, but not $n-6$ polyunsaturated, fatty acids induce insulin resistance: role of intramuscular accumulation of lipid metabolites. J Appl Physiol 2006; 100: 1467-74.

32 Gaster M, Rustan AC, Beck-Nielsen H. Differential utilization of saturated palmitate and unsaturated oleate: evidence from cultured myotubes. Diabetes 2005; 54: 648-56.

33 Yu HY, Inoguchi T, Kakimoto M, Nakashima N, Imamura M, Hashimoto $\mathrm{T}$, et al. Saturated non-esterified fatty acids stimulate de novo diacylglycerol synthesis and protein kinase c activity in cultured aortic smooth muscle cells. Diabetologia 2001; 44: 614-20.

34 Way KJ, Katai N, King GL. Protein kinase C and the development of diabetic vascular complications. Diabet Med 2001; 18: 945-59.

35 Lee IK, Koya D, Ishi H, Kanoh H, King GL. d-Alpha-tocopherol prevents the hyperglycemia induced activation of diacylglycerol (DAG)-protein kinase $\mathrm{C}(\mathrm{PKC})$ pathway in vascular smooth muscle cell by an increase of DAG kinase activity. Diabetes Res Clin Pract 1999; 45: 183-90.

36 Ebbesson So, Roman MJ, Devereux RB, Kaufman D, Fabsitz RR, Maccluer JW, et al. Consumption of omega-3 fatty acids is not associated with a reduction in carotid atherosclerosis: the Genetics of Coronary Artery Disease in Alaska Natives study. Atherosclerosis 2008; 199: 346-53.

37 Rodríguez-Lee M, Ostergren-Lundén G, Wallin B, Moses J, Bondjers G, Camejo G. Fatty acids cause alterations of human arterial smooth muscle cell proteoglycans that increase the affinity for low-density lipoprotein. Arterioscler Thromb Vasc Biol 2006; 26: 130-5.

38 Rho MC, Ah Lee K, Mi Kim S, Sik Lee C, Jeong Jang M, Kook Kim Y, et al. Sensitization of vascular smooth muscle cell to TNF-alphamediated death in the presence of palmitate. Toxicol Appl Pharmacol 2007; 220: 311-9.

39 Kedi X, Ming Y, Yongping W, Yi Y, Xiaoxiang Z. Free cholesterol overloading induced smooth muscle cells death and activated both ER- and mitochondrial-dependent death pathway. Atherosclerosis 2009; 207: 123-30.

40 Khan MI, Pichna BA, Shi Y, Bowes AJ, Werstuck GH. Evidence supporting a role for endoplasmic reticulum stress in the development of atherosclerosis in a hyperglycaemic mouse model. Antioxid Redox Signal 2009; 11: 2289-98.

41 Cheng WP, Hung HF, Wang BW, Shyu KG. The molecular regulation of GADD153 in apoptosis of cultured vascular smooth muscle cells by 
cyclic mechanical stretch. Cardiovasc Res 2008; 77: 551-9.

42 Chin TY, Lin HC, Kuo JP, Chueh SH. Dual effect of thapsigargin on cell death in porcine aortic smooth muscle cells. Am J Physiol Cell Physiol 2007; 292: C383-95.

43 Werstuck GH, Khan MI, Femia G, Kim AJ, Tedesco V, Trigatti B, et al. Glucosamine-induced endoplasmic reticulum dysfunction is associated with accelerated atherosclerosis in a hyperglycemic mouse model. Diabetes 2006; 55: 93-101.

44 Baumann S, Fas SC, Giaisi M, Müller WW, Merling A, Gülow K, et al. Wogonin preferentially kills malignant lymphocytes and suppresses T-cell tumor growth by inducing PLC\{gamma\}1- and $\mathrm{Ca}^{2+}$-dependent apoptosis. Blood 2008; 111: 2354-63.

45 Lee DH, Kim C, Zhang L, Lee YJ. Role of p53, PUMA, and Bax in Wogonin induced apoptosis in human cancer cells. Biochem Pharmacol 2008; 75: 2020-33.

46 Enomoto R, Sugahara C, Suzuki C, Nagase I, Takamura Y, Yoshikawa A, et al. Wogonin prevents glucocorticoid-induced thymocyte apoptosis without diminishing its anti-inflammatory action. J Pharmacol Sci 2007; 104: 355-65.

47 Havsteen $\mathrm{BH}$. The biochemistry and medical significance of the flavonoids. Pharmacol Ther 2002; 96: 67-202.

48 Rice-Evans CA, Miller NJ, Paganga G. St ructure-antioxidant activity relationships of flavonoids and phenolic acids. Free Radic Biol Med 1996; 20: 933-56.
49 Cao G, Sofic E, Prior RL. Antioxidant and prooxidant behavior of flavonoids: structure-activity relationships. Free Radic Biol Med 1997; 22: 749-60.

50 Lambertucci RH, Hirabara SM, Silveira Ldos R, Levada-Pires AC, Curi $\mathrm{R}$, Pithon-Curi TC. Palmitate increases superoxide production through mitochondrial electron transport chain and NADPH oxidase activity in skeletal muscle cells. J Cell Physiol 2008; 216: 796-804.

51 Inoguchi T, Li P, Umeda F, Yu HY, Kakimoto M, Aoki T, et al. High glucose level and free fatty acid stimulate reactive oxygen species production through protein kinase C-dependent activation of $\mathrm{NAD}(\mathrm{P}) \mathrm{H}$ oxidase in cultured vascular cells. Diabetes 2000; 49: 1939-45.

52 Mattern HM, Hardin CD. Vascular metabolic dysfunction and lipotoxicity. Physiol Res 2007; 56: 149-58.

53 Hickson-Bick DL, Sparagna GC, Buja LM, McMillin JB. Palmitateinduced apoptosis in neonatal cardiomyocytes is not dependent on the generation of ROS. Am J Physiol Heart Circ Physiol 2002; 282: H656-64.

54 Pino SC, O'Sullivan-Murphy B, Lidstone EA, Thornley TB, Jurczyk A, Urano $\mathrm{F}$, et al. Protein kinase $\mathrm{C}$ signaling during $\mathrm{T}$ cell activation induces the endoplasmic reticulum stress response. Cell Stress Chaperones 2008; 13: 421-34.

55 Lee W, Kim DH, Boo JH, Kim YH, Park IS, Mook-Jung I. ER stressinduced caspase-12 activation is inhibited by PKC in neuronal cells. Apoptosis 2005; 10: 407-15. 